\title{
MR Imaging of the Olfactory Bulbs in Patients with COVID-19 and Anosmia: How to Avoid Misinterpretation
}

W e recently read the article entitled "Brain Imaging of Patients with COVID-19: Findings at an Academic Institution during the Height of the Outbreak in New York City," a retrospective neuroimaging cohort by Lin et al. ${ }^{1}$ The authors reported T2-FLAIR postgadolinium olfactory bulb (OB) signal abnormalities in 4 patients positive for coronavirus disease 2019 (COVID-19) with only 1 having documented anosmia. This finding was subsequently interpreted as olfactive neuritis and a correlate of the anosmia.

Anosmia has been identified as one of the first or only recognizable symptoms of the Severe Acute Respiratory Syndrome coronavirus 2 (SARS-CoV-2) infection, accounting for $>50 \%$ of Western patients. $^{2}$ It is now known that post-SARS-CoV-1 anosmia could persist for as long as 2 years. It, thus, becomes relevant to identify MR imaging biomarkers of $\mathrm{OB}$ involvement, including signal and volume changes, that might be predictive of the olfactory disorder outcome. We, thus, find it important to draw the attention to the OB signal and volume analysis.

The OB signal intensity can vary according to the field strength applied, the MR imaging manufacturer, and the acquisition parameters of T2-FLAIR sequences. Furthermore, it has previously been reported that OBs could appear hyperintense on T2FLAIR in healthy subjects. ${ }^{3}$ Lin et $\mathrm{al}^{1}$ reported that they recruited patients who had undergone brain MR imaging from 3 different machines (1.5T and $3 \mathrm{~T})$, increasing the risk of signal variation in tiny structures and thus making the results more questionable.

Age- and sex-matched healthy controls scanned on the same MR imaging scanner need to be analyzed to overcome these technical issues and avoid an incorrect OB edema/gadoliniumenhancement description. In our institution, a blind, independent comparison by 2 experienced neuroradiologists of 10 patients with COVID-19-associated anosmia and 10 age- and sex-matched subjects negative for COVID-19 without olfactory dysfunction was performed. It showed that visual analysis of OB high-resolution T2FLAIR signal could not distinguish the 2 groups because all the subjects presented with the same T2-FLAIR high signal intensity (Fig 1).

- Indicates open access to non-subscribers at www.ajnr.org

http://dx.doi.org/10.3174/ajnr.A6921

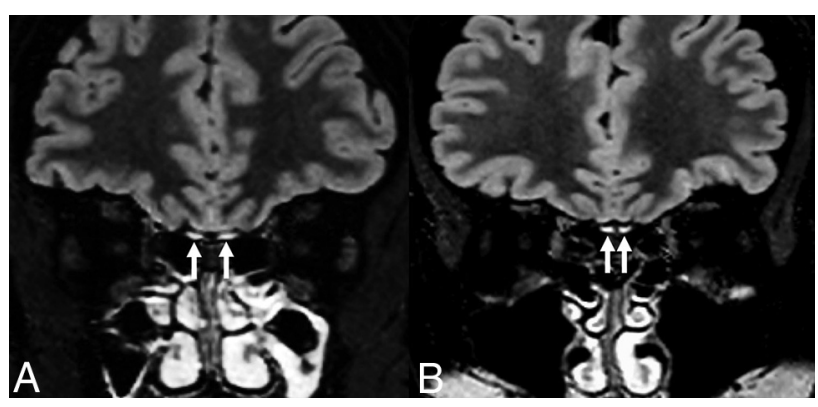

FIG 1. 3T brain MR imaging in a healthy subject $(A)$ and a patient with COVID-19-related anosmia (B). Coronal reformatted 3D FLAIR images show OB hyperintensity (arrows) compared with the cortex in both subjects.

Thus, the OBs described by Lin et $\mathrm{al}^{1}$ as being abnormally "hyperintense" can probably correspond to a normal signal intensity.

It has been shown that the $\mathrm{OB}$ volume decreased in postinfectious anosmia. ${ }^{4}$ Because the OBs are tiny structures surrounded by CSF, sequences with high resolution such as CISS should be used for volume segmentation. As for the signal on an individual scale, the signal intensity evolution of the OB could be compared with the surrounding structures, such as the cortex or the optic nerves. Subjective appreciation, especially for such a small structure, could lead to misinterpretation.

In summary, $\mathrm{OB}$ imaging is challenging, and one should be careful while interpreting its signal and volume, especially in the context of COVID-19.

Disclosures: Nadya Pyatigorskaya_UNRELATED: Employment: Assistance publiqueHôpitaux de Paris; Grants/Grants Pending: CRC, Progressive Supranuclear Palsy (PSP)-France*; Payment for Lectures Including Service on Speakers Bureaus: GE Healthcare, Biogen. *Money paid to the institution.

\section{REFERENCES}

1. Lin E, Lantos JE, Strauss SB, et al. Brain imaging of patients with COVID-19: findings at an academic institution during the height of the outbreak in New York City. AJNR Am J Neuroradiol 2020 Aug 20. [Epub ahead of print] CrossRef Medline

2. Lechien JR, Chiesa-Estomba CM, Hans S, et al. Loss of smell and taste in 2013 European patients with mild to moderate COVID-19. Ann Intern Med 2020 May 26. [Epub ahead of print] CrossRef Medline 
3. Chung MS, Choi WR, Jeong HY, et al. MR imaging-based evaluations of olfactory bulb atrophy in patients with olfactory dysfunction. AJNR Am J Neuroradiol 2018;39:532-37 CrossRef Medline

4. Yao L, Yi X, Pinto JM, et al. Olfactory cortex and olfactory bulb volume alterations in patients with post-infectious olfactory loss. Brain Imaging Behav 2018;12:1355-62 CrossRef Medline

(1) N. Shor

Service de Neuroradiologie Assistance Publique Hôpitaux de Paris, Hôpital Pitié-Salpêtrière Paris, France
(D). Chougar

DN. Pyatigorskaya

Service de Neuroradiologie Assistance Publique Hôpitaux de Paris, Hôpital Pitié-Salpêtrière

Paris, France

Paris Brain Institute Sorbonne Université

Paris, France

"Movement Investigations and Therapeutics" Team

Centre de Neurolmagerie de Recherche Institut du Cerveau

Paris, France 